\title{
INDUÇÃO DE CALOS EM EXPLANTES FOLIARES DE MURICI-PEQUENO (Byrsonima intermedia A. Juss.)
}

\author{
Calli induction from leaf explants of murici-pequeno (Byrsonima intermedia A. Juss.)
}

\author{
Raírys Cravo Nogueira', Renato Paiva ${ }^{2}$, Lenaldo Muniz de Oliveira ${ }^{3}$, Gustavo de Araújo Soares ${ }^{4}$, \\ Fernanda Pereira Soares ${ }^{5}$, Ana Hortência Fonseca Castro ${ }^{6}$, Patrícia Duarte de Oliveira Paiva ${ }^{7}$
}

\begin{abstract}
RESUMO
O murici-pequeno (Byrsonima intermedia A. Juss.) é um arbusto do cerrado cujo chá da casca do caule apresenta atividade adstringente nas diarréias e disenterias. O gênero Byrsonima apresenta taxa de germinação baixa e emergência lenta da plântula, dificultando a propagação sexuada. Objetivou-se com este trabalho obter calos friáveis em explantes foliares de murici-pequeno para estudos futuros em suspensão celular e metabolismo secundário, assim como embriogênese somática. Avaliou-se o efeito de diferentes concentrações da auxina 2,4-D e a sua interação com as citocininas TDZ e BAP na calogênese. Os resultados demonstraram que na ausência de 2,4-D não ocorre formação de calo em explantes foliares. A adição de BAP ou TDZ não influencia o processo de calogênese. Para a indução e proliferação de calo em explantes foliares de murici-pequeno, os resultados recomendam o uso de meio MS, acrescido de 1,0 $\mathrm{mg} \mathrm{L}^{-1}$ de 2,4-D, mantendo os explantes em condição de escuro por 30 dias.
\end{abstract}

Termos para indexação: Murici-pequeno, calogênese, fitorreguladores, Byrsonima intermedia in vitro.

\section{ABSTRACT}

Byrsonima intermedia A. Juss is a shrub of cerrado whose husk presents medicinal activities in diarrheas and dysenteries. The Byrsonima genus present low germination rate and slow plantlet emergency which makes difficult sexual propagation. The objective of this work was to obtain friable callus in leaf explants for future studies with suspension cells and secondary metabolites as well as somatic embryogenesis. The effect of different concentrations of 2,4-D and its interaction with TDZ and BAP in callus formation was evaluated. The results demonstrated that there is no formation of callus in leaf explants maintained in absence of 2,4-D. The addition of TDZ or BAP had no influence in the calogenesis process. For callus induction and proliferation, the results suggest the use of MS medium supplemented with $1.0 \mathrm{mg} \mathrm{L}^{-1} 2,4-\mathrm{D}$ maintaining the explants in the dark.

Index terms: Murici-pequeno, calogenesis, phytohormones.

\section{(Recebido em 10 de fevereiro de 2005 e aprovado em 5 de setembro de 2005)}

\section{INTRODUÇÃOO}

O murici-pequeno (Byrsonima intermedia A. Juss.), um arbusto do cerrado, apresenta atividade adstringente nas diarréias e disenterias a partir do chá da casca do caule (RODRIGUES \& CARVALHO, 2001). Lorenzi (2002) menciona que o gênero Byrsonima apresenta taxa de germinação baixa e emergência lenta da plântula, dificultando a sua propagação sexuada.

A aplicação de técnicas de cultura de tecidos vegetais, como a micropropagação, tem como principais vantagens o aumento rápido do número de indivíduos e a possibilidade de conservação de germoplasma, garantindo a manutenção da biodiversidade (ECHEVERRIGARAY et al., 2001).
Uma das maneiras de multiplicação é por meio da organogênese indireta, passando pela fase de calo. Para ocorrer a indução de calo, qualquer tecido vegetal pode ser utilizado como explante. Entretanto, procura-se utilizar explantes que contenham maior proporção de tecido meristemático ou que apresentem maior capacidade de expressar a totipotência (GRATTAPAGLIA \& MACHADO, 1998). Explantes oriundos de tecidos jovens, não lignificados, são mais apropriados para a cultura de calo (PIERIK, 1990).

De acordo com Vietez \& San-José (1996), muitas vezes é necessário o suprimento exógeno de reguladores de crescimento para a indução de calo. O balanço hormonal obtido entre os níveis de citocininas e auxinas, exógenas e

\footnotetext{
'Doutora em Agronomia, Fisiologia Vegetal - Departamento de Biologia/DBI - Universidade Federal de Lavras/UFLA - Cx. P. 3037 - $37.200-000$ Lavras, MG - rairys@yahoo.com.br

${ }^{2}$ Professor, Departamento de Biologia/DBI - Universidade Federal de Lavras/UFLA - Cx. P. 3037 - 37.200-000 - Lavras, MG - renpaiva@ufla.br ${ }^{3}$ Doutor em Fisiologia Vegetal - Departamento de Biologia/DBI - Universidade Federal de Lavras/UFLA - Cx. P. 3037 - $37.200-000$ - Lavras, MG. ${ }^{4}$ Doutorando, Departamento de Botânica - Universidade Federal de Minas Gerais/UFMG.

${ }^{5}$ Doutoranda Fisiologia Vegetal - Departamento de Biologia/DBI - Universidade Federal de Lavras/UFLA - Cx. P. 3037 - $37.200-000$ - Lavras, MG. ${ }^{6}$ Professora do Curso de Farmácia/Bioquímica - Centro Universitário de Lavras /UNILAVRAS - Rua Padre José Poggel, 506 - Centenário - $37.200-000$ Lavras, MG.

${ }^{7}$ Professora do Departamento de Agricultura - Universidade Federal de Lavras/UFLA - Cx. P. 3037 - 37.200-000 - Lavras, MG - pdolivei@ufla.br
} 
endógenas à planta, pode estimular a proliferação celular. Porém, Ozias-Akins \& Vasil (1985) mencionam que citocininas exógenas nem sempre são necessárias e que muitos tecidos desenvolvem-se in vitro apenas com suprimento de auxinas. Dentre os reguladores de crescimento mais utilizados na indução de calo destacamse o 2,4-D e, mais recentemente, o TDZ. Segundo Lu (1993), o TDZ estimula a divisão celular e, conseqüientemente, o crescimento de calos dependentes de citocininas em algumas espécies.

Objetivou-se com este trabalho obter calos friáveis em explantes foliares de murici-pequeno para aplicação em suspensões celulares, possibilitando estudos futuros na área de embriogênese somática e/ou metabólitos secundários. Com o presente trabalho, avaliou-se o efeito de diferentes concentrações da auxina 2,4-D e sua interação com as citocininas TDZ e BAP na indução de calogênese em explantes foliares.

\section{MATERIAL E MÉTODOS}

Indução de calo através do uso de 2,4-D na presença e ausência de luz

Segmentos foliares com tamanho aproximado de $0,25 \mathrm{~cm}^{2}$ foram excisados de plântulas pré-estabelecidas in vitro. Os explantes foram inoculados em tubos de ensaio contendo o meio de cultura MS (MURASHIGE \& SKOOG, 1962) suplementado com diferentes concentrações de 2,4$\mathrm{D}\left(0,0 ; 1,0 ; 2,0 ; 3,0\right.$ e $\left.4,0 \mathrm{mg} \mathrm{L}^{-1}\right)$ e $3 \%$ de sacarose. O meio foi solidificado com $0,7 \%$ de ágar e o pH ajustado em 5.8, antes da autoclavagem.

Antes da inoculação, foram efetuados cortes na superfície adaxial do explante, aumentando a área de contato com o meio nutritivo. A incubação foi realizada na ausência e presença de luz (com fotoperíodo de $16 \mathrm{~h}$ e irradiância de fótons de $\left.43 \mu \mathrm{mol} \mathrm{m} \mathrm{m}^{-2} \mathrm{~s}^{-1}\right)$ e em temperatura de $27 \pm 2^{\circ} \mathrm{C}$.

Utilizou-se o delineamento inteiramente casualizado, em fatorial 2 (luz e escuro) x 5 (cinco concentrações de 2,4-D: 0,0; 1,0; 2,0; 3,0 ou 4,0 mg L'-1), com cinco repetições por tratamento, sendo cada repetição composta por quatro tubos de ensaio contendo um explante por tubo. A avaliação foi realizada por três avaliadores observando a porcentagem da área do explante ocupada por calo, aos 30 dias após a inoculação.

Efeito da interação entre 2,4-D e as citocininas TDZ e BAP

Segmentos foliares com tamanho aproximado de $0,25 \mathrm{~cm}^{2}$ foram excisados de plântulas pré-estabelecidas in vitro. Os explantes foram inoculados em tubos de ensaio contendo o meio de cultura MS suplementado com a auxina 2,4-D ( 0,0 ou 1,0 $\left.\mathrm{mg} \mathrm{L}^{-1}\right)$ em combinação com diferentes concentrações $\left(0,0 ; 0,5 ; 1,0\right.$ e $\left.2,0 \mathrm{mg} \mathrm{L}^{-1}\right)$ das citocininas BAP ou TDZ e $3 \%$ de sacarose. O meio foi solidificado com $0,7 \%$ de ágar e seu $\mathrm{pH}$ ajustado para 5,8 antes da autoclavagem.

Antes da inoculação, foram efetuados cortes na superfície adaxial do explante para aumentar a área de contato com o meio nutritivo. A incubação ocorreu no escuro e em temperatura de $27 \pm 2^{\circ} \mathrm{C}$.

Utilizou-se o delineamento inteiramente casualizado, em fatorial 2 (auxina) x 2 (BAP x TDZ) x 4 (doses), com quatro repetições por tratamento, sendo cada repetição composta por três tubos de ensaio contendo um explante por tubo. A avaliação foi realizada por três avaliadores observando-se a porcentagem da área do explante ocupada por calo, aos 30 dias após a inoculação.

\section{RESULTADOS E DISCUSSÃO}

$\mathrm{Na}$ indução de calo em explantes foliares de muricipequeno, diferenças significativas em relação à área do explante coberta por calo foram encontradas em função da manutenção dos explantes na ausência ou presença de luminosidade, das concentrações de 2,4-D e da interação entre estes fatores.

Na presença de luz, os tratamentos seguiram uma tendência linear, indicando que quanto maior era dose de 2,4-D, maior era a área do explante coberta por calo (Figura 1).

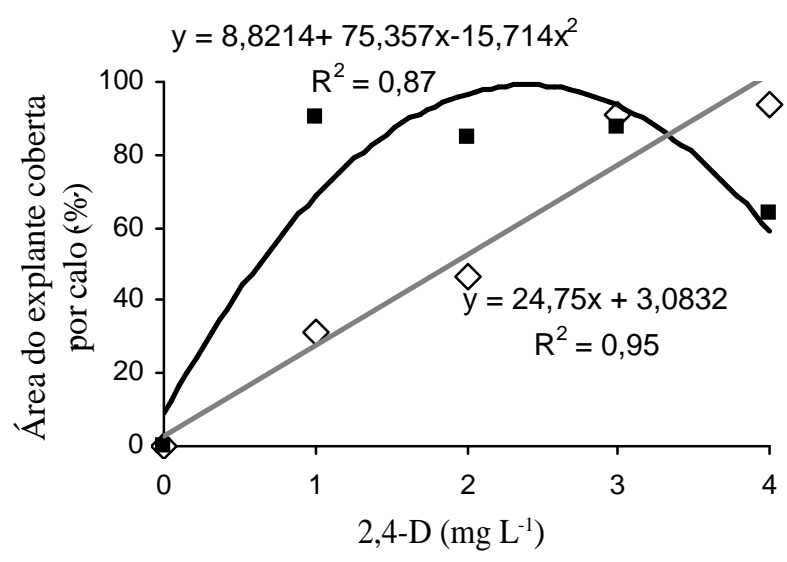

FIGURA 1 - Área dos explantes foliares de murici-pequeno ocupada por calo em diferentes concentrações de 2,4-D e mantidos na ausência $(\boldsymbol{\nabla})$ e presença $(\diamond)$ de luz. 
Na ausência de luminosidade, a dose $0,0 \mathrm{mg} \mathrm{L}^{-1} \mathrm{de}$ 2,4-D não produziu calos. A curva apresentou tendência quadrática, em que a dose de $2,4 \mathrm{mg} \mathrm{L}^{-1}$ de 2,4-D correspondeu ao ponto máximo da curva, atingindo cobertura máxima de $99,18 \%$, de acordo com a equação derivada. Este comportamento quadrático indicou que concentrações acima e abaixo de $2,4 \mathrm{mg} \mathrm{L}^{-1}$ tiveram tendência de redução da porcentagem de área coberta por calo.

O 2,4-D é a auxina mais freqüentemente usada na indução de calogênese e, no caso do murici-pequeno, explantes foliares responderam positivamente à sua presença. As auxinas são capazes de iniciar a divisão celular e controlar os processos de crescimento e elongação celular. George (1996) comenta que o 2,4-D tem efeito no metabolismo do RNA, induzindo a transcrição de RNAs mensageiros capazes de decodificar proteínas para o crescimento e que podem induzir a proliferação celular desordenada.

$\mathrm{O}$ crescimento de tecidos vegetais organizados in vitro geralmente não é inibido pela luz. Entretanto, divisões celulares iniciais do explante e o crescimento de calo podem ser inibidos pela presença de luz (GEORGE, 1996). Vale ressaltar que a adição de 2,4-D numa concentração quatro vezes maior $\left(4,0 \mathrm{mg} \mathrm{L}^{-1}\right)$ foi necessária para proporcionar resposta semelhante quando na presença de luz.

A presença de luz pode ter favorecido a produção de compostos fenólicos, os quais interferiram na atividade do regulador de crescimento e refletiram em maior concentração deste para atingir a porcentagem obtida no escuro. A auxina natural (AIA) presente no tecido vegetal também pode ter sofrido foto-degradação, diminuindo as quantidades de auxinas totais que desencadeariam o processo de formação de calo.

Quanto ao efeito da interação de 2,4-D e das citocininas TDZ e BAP na indução de calogênese em explantes foliares de murici-pequeno, observou-se que as áreas cobertas por calos foram significativamente maiores quando os explantes foram inoculados na presença de 2,4$\mathrm{D}$, evidenciando que a presença desta auxina é essencial no processo de calogênese.

Observa-se que com o aumento da concentração de citocinina, a porcentagem de calos diminui na presença de 2,4-D, enquanto que na ausência de 2,4-D ocorre um ligeiro aumento na porcentagem sem diferenças estatísticas. O tipo de citocinina utilizado (TDZ ou BAP) não afetou a formação de calos, havendo, porém, influência para a dose utilizada (Figura 2).

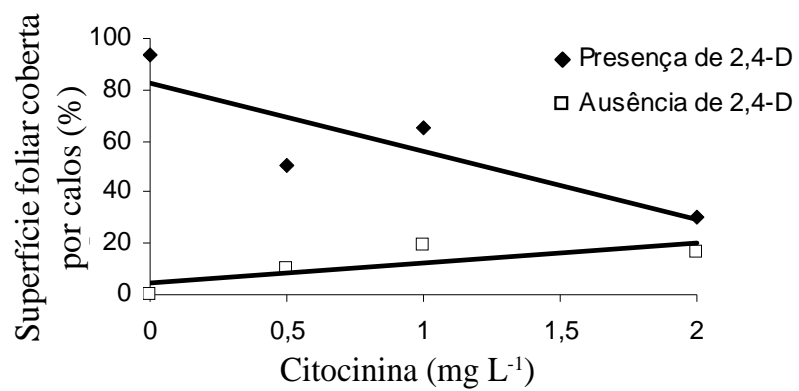

FIGURA 2 - Gráfico da regressão da concentração dentro dos níveis de 2,4-D.

Como a indução de calo é dependente de um balanço hormonal intermediário de auxinas e citocininas, no caso do murici-pequeno, provavelmente, o fornecimento da auxina no meio de cultura foi suficiente para balancear o conteúdo endógeno de citocininas do explante.

Assim, os resultados indicam que a citocinina (BAP) presente no meio nutritivo, juntamente com a citocinina endógena do segmento foliar, possivelmente proporcionaram uma elevada concentração deste regulador em relação à auxina, ocasionando uma diminuição na formação de calo.

Os resultados deste trabalho são semelhantes aos obtidos por Abreu (1998), Bonilla (2002), Conceição (2000), Paiva-Neto (1996), Santos, B. (2001), Santos, C. (2001) e Soares (2003) trabalhando com segmentos foliares de Inga vera Willd subsp. affinis (DC.) T.D. Penn., Cissus sicyoides Linn., Coffea arabica Linn., Derris urucu (Killip \& Smith) Macbr., Rudgea viburnoides (Cham.) Benth. e Chlorophora tinctoria Gaudich., respectivamente.

Entretanto, Sahoo et al. (1997), testando concentrações de 0,5 a 4,0 $\mathrm{mg} \mathrm{L}^{-1}$ de 2,4-D, observaram que não houve a formação de calos a partir de explantes foliares de amoreira (Morus indica Linn.).

Cerqueira (1999) obteve maior indução de calo em segmentos foliares de erva-de-touro (Tridax procumbens Linn.) utilizando $2,0 \mathrm{mg} \mathrm{L}^{-1}$ de ANA combinado com 2,0 $\mathrm{mg} \mathrm{L}^{-1}$ de BAP, obtendo $100 \%$ da área do explante coberta por calo.

Em copaíba (Copaifera langsdorffii Desf.), Azevedo (2003) somente obteve calogênese utilizando 2,0 $\mathrm{mg} \mathrm{L}^{-1}$ de 2,4-D + 1,0 $\mathrm{mg} \mathrm{L}^{-1}$ de BAP em meio MS na presença de luz.

Cavalcante (2001) observou que quando o TDZ foi combinado com o 2,4-D não foi observada a iniciação de calos friáveis e que as concentrações de 2 e 3 uM de TDZ induziram as maiores frequências de explantes foliares com 
calos friáveis em cupuaçu (Theobroma grandiflorum (Willd ex Spreng) Schum).

Assim, os resultados indicam que a máxima porcentagem de calo em segmentos foliares de muricipequeno é obtida em meio MS acrescido de $1,0 \mathrm{mg} \mathrm{L}^{-1} \mathrm{de}$ 2,4-D e na ausência de luz, e que a interação desta auxina com uma citocinina (TDZ ou BAP) não promove maior indução de calo.

\section{CONCLUSÕES}

Nas condições descritas neste trabalho:

Não se verificou a indução de calogênese em explantes foliares de murici-pequeno, na ausência de 2,4-D.

Não se verificou efeito positivo da utilização de BAP ou TDZ em interação com 2,4-D na calogênese em explantes foliares de murici-pequeno.

Para a indução de calos em explantes foliares de murici-pequeno, recomenda-se o uso de meio MS acrescido de 2,4 $\mathrm{mg} \mathrm{L}^{-1}$ de 2,4-D, mantendo-se os explantes em condição de escuro.

\section{REFERÊNCIAS BIBLIOGRÁFICAS}

ABREU, I. N. Propagação in vivo e in vitro, calogênese, nutrição mineral e quantificação de mucilagem em Cissus sicyoides. 1998. 101 p. Dissertação (Mestrado em Fisiologia Vegetal) - Universidade Federal de Lavras, Lavras, 1998.

AZEVEDO, K. de S. Indução e análises bioquímicas de calo e aspectos da anatomia foliar de copaíba (Copaifera langsdorffii Desf.). 2003. 86 p. Dissertação (Mestrado em Fitotecnia) - Universidade Federal de Lavras, Lavras, 2003.

BONILLA, M. G. O. Propagação in vivo, indução, curva de crescimento de calo e abordagem fitoquímica em $\mathbf{R}$ udgea viburnoides (CHAM) Benth. 2002. 162 p. Tese (Doutorado em Fitotecnia) - Universidade Federal de Lavras, Lavras, 2002.

CAVALCANTE, A. da S. L. Resposta morfogenéticas in vitro de acaizeiro (Euterpe oleracea Mart.) e de cupuaçuzeiro (Theobroma grandiflorum (Wild. ex Spreng.) Schum.). 2001. 124 f. Tese (Doutorado em Fitotecnia) - Universidade Federal do Ceará, Fortaleza, 2001.

CERQUEIRA, E. S. Propagação e calogênese in vitro em erva-de-touro (Tridax procumbens L.), uma planta medicinal. 1999. 81 p. Dissertação (Mestrado em Fisiologia Vegetal) - Universidade Federal de Lavras, Lavras, 1999.
CONCEIÇÃO, H. E. O. da. Cultivo in vitro, nutrição mineral e quantificação de rotenóides em timbós (Derris sp). 2000. 191 p. Tese (Doutorado em Fitotecnia) - Universidade Federal de Lavras, Lavras, 2000.

ECHEVERRIGARAY, S.; ANDRADE, L. B.; DELAMARE, A. P. L.; ZENI, A. L. B.; CARRER, R. Cultura de tecidos e micropropagação de plantas aromáticas e medicinais. In: TORRES, A. C.; CALDAS, L. S.; BUSO, J. A. Biotecnologia na agricultura e na agroindústria. Guaíba: Agropecuária, 2001. p. 257-276.

GEORGE, E. F. Plant propagation by tissue culture: part 1: the technology. Edington: Exegetics, 1996. 574 p.

GRATTAPAGLIA, D.; MACHADO, M. A. Micropropagação. In: TORRES, A. C.; CALDAS, L. S.; BUSO, J. A. (Eds.). Cultura de tecidos e transformação genética de plantas. Brasília, DF: Embrapa-SPI/EmbrapaCNPH, 1998. v. 1, p. 183-260.

LORENZI, H. Árvores brasileiras: manual de identificação e cultivo de plantas arbóreas nativas do Brasil. São Paulo: Nova Odessa, 2002. v. 1, 386 p.

LU, C. The use of thidiazuron in tissue cultures. In Vitro, Cellular and Developmental Biology Plant, Oxon, v. 29, n. 2, p. 92-96, 1993.

MURASHIGE, T.; SKOOG, F. A revised medium for rapid growth and bioassays with tobacco tissue cultures. Physiologia Plantarum, Copenhagen, v. 15, n. 3, p. 473497, 1962.

OZIAS-AKINS, P.; VASIL, I. K. Nutrition of plant tissue cultures. In: VASIL, I. K. (Ed.). Cell culture and somatic cell genetics of plants: cell growth, nutrition, cytodifferenciation and cryopreservation. Florida: Academic, 1985. v. 2, p. 128-147.

PAIVA-NETO, V. B. Comportamento in vitro de tecido foliar e segmento nodal de moreira (Chlorophora tinctoria $(\mathrm{L}$. Gaudichaud). 1996. 39 f. Dissertação (Mestrado em Fisiologia Vegetal) - Universidade Federal de Lavras, Lavras, 1996.

PIERIK, R. L. M. Cultivo in vitro de las plantas superiores. Martins: Nijoff, 1990. 326 p. 
RODRIGUES, V. E. G.; CARVALHO, D. A. de. Plantas medicinais no domínio dos cerrados. Lavras: UFLA, 2001. $180 \mathrm{p}$.

SAHOO, Y.; PATTNAIK, S. K.; CHAND, P. K. Plant regeneration from callus cultures of Morus indica $\mathrm{L}$. derved from seedlings and mature plants. Scientia Horticulturae, Amsterdam, v. 69, n. 1/2, p. 85-98, 1997.

SANTOS, B. R. Propagação in vitro e abordagem fitoquímica em salix (Salix humbolditiana Willd.). 2001. 89 p. Dissertação (Mestrado em Fisiologia Vegetal) - Universidade Federal de Lavras, Lavras, 2001.
SANTOS, C. G. Micropropagação e caracterização bioquímico-anatômica em Coffea arabica e Coffea canephora. 2001. 110 p. Dissertação (Mestrado em Fisiologia Vegetal) - Universidade Federal de Lavras, Lavras, 2001.

SOARES, G. de A. Aspectos do cultivo in vitro do ingazeiro [Inga vera Willd. subsp. affinis (DC) T. D. Penn.]. 2003. 90 p. Dissertação (Mestrado em Fisiologia Vegetal) Universidade Federal de Lavras, Lavras, 2003.

VIETEZ, A. M.; SAN-JOSÉ, M. C. Adventitious shoot regeneration from Fagus sylvatica leaf explants in vitro. In vitro Cellular \& Developmental Biology, Columbia, v. 32, n. 3, p. 140-147, 1996. 